\title{
Bacterial feeding, Leishmania infection and distinct infection routes induce differential defensin expression in Lutzomyia longipalpis
}

Erich L Telleria ${ }^{1,3,4}$, Maurício R Viana Sant'Anna², Mohammad O Alkurbi ${ }^{3}$, André N Pitaluga' ${ }^{1}$, Rod J Dillon ${ }^{2}$ and Yara M Traub-Csekö ${ }^{*}$

\begin{abstract}
Background: Phlebotomine insects harbor bacterial, viral and parasitic pathogens that can cause diseases of public health importance. Lutzomyia longipalpis is the main vector of visceral leishmaniasis in the New World. Insects can mount a powerful innate immune response to pathogens. Defensin peptides take part in this response and are known to be active against Gram-positive and Gram-negative bacteria, and some parasites. We studied the expression of a defensin gene from Lutzomyia longipalpis to understand its role in sand fly immune response.

Methods: We identified, sequenced and evaluated the expression of a L. longipalpis defensin gene by semi-quantitative RT-PCR. The gene sequence was compared to other vectors defensins and expression was determined along developmental stages and after exposure of adult female L. longipalpis to bacteria and Leishmania.

Results: Phylogenetic analysis showed that the L. longipalpis defensin is closely related to a defensin from the Old World sand fly Phlebotomus duboscai. Expression was high in late L4 larvae and pupae in comparison to early larval stages and newly emerged flies. Defensin expression was modulated by oral infection with bacteria. The Gram-positive Micrococcus luteus induced early high defensin expression, whilst the Gram-negative entomopathogenic Serratia marcescens induced a later response. Bacterial injection also induced defensin expression in adult insects. Female sand flies infected orally with Leishmania mexicana showed no significant difference in defensin expression compared to blood fed insects apart from a lower defensin expression 5 days post Leishmania infection. When Leishmania was introduced into the hemolymph by injection there was no induction of defensin expression until $72 \mathrm{~h}$ later.
\end{abstract}

Conclusions: Our results suggest that L. longipalpis modulates defensin expression upon bacterial and Leishmania infection, with patterns of expression that are distinct among bacterial species and routes of infection.

Keywords: Lutzomyia longipalpis, Defensin, Leishmania, Bacteria

\section{Background}

Sand flies are vectors of bacterial and parasitic diseases such as bartonellosis and leishmaniasis [1,2]. Lutzomyia longipalpis is the main vector of Leishmania infantum chagasi, the causative agent of visceral leishmaniasis in South America [2]. Although little is known about sand fly responses to bacterial infection, several studies have

\footnotetext{
*Correspondence: ytraub@ioc.fiocruz.br

${ }^{1}$ Laboratório de Biologia Molecular de Parasitos e Vetores, Instituto Oswaldo Cruz-Fiocruz, Rio de Janeiro, RJ, Brazil

Full list of author information is available at the end of the article
}

focused on molecular events that occur during the establishment of Leishmania infection in the insect [3]. Leishmania molecules such as lipophosphoglycan (LPG) [4] and chitinase [5] have been shown to contribute to the success of Leishmania infections in sand flies. Additionally, sand fly molecules such as galectin receptors [6], digestive proteases $[7,8]$ and a physical barrier such as the peritrophic matrix [9] have been shown to have an important role in Leishmania survival within the sand fly gut.

\section{Ciomed Central}


Several studies have described the natural gut microbiota in Old World [10-12] and New World sand flies [13-16] although mechanisms by which sand flies control the microbial balance in the gut are still unknown.

Insects are capable of mounting a complex repertoire of immune responses to maintain gut homeostasis and eliminate pathogens. Cellular responses include phagocytosis by hemocytes and melanotic encapsulation of pathogenic microorganisms through the activation of the phenoloxidase cascade [17]. Humoral responses, on the other hand, lead to the synthesis of a wide range of effector molecules, including antimicrobial peptides (AMPs) [18-20]. AMPs have been described in many insects as having a central role in innate immune responses against bacterial and parasitic infections [21-23]. Among these, defensin (a $4 \mathrm{kDa}$ cationic peptide) has been identified in several insects [23-26] and shown to have a deleterious effect on bacteria [26], Plasmodium [27] and Leishmania [28,29]. Defensin was shown to be upregulated in Phlebotomus duboscqi upon Leishmania major infection [29]. Here we identified, sequenced and investigated the expression profile of a L. longipalpis defensin throughout the sand fly developmental stages, after Gram-positive and Gram-negative bacterial challenges and after sand fly infection with Leishmania mexicana.

\section{Methods}

\section{Defensin gene sequence analysis}

Partial L. longipalpis defensin gene (LIDef1) sequences were obtained from our previous database [30,31] and the full genomic sequence was obtained using primers designed to target the 5'UTR and 3'UTR regions (LIDef1F 5'-TTGGTCATAGCGTGCAGAAG-3' and LIDef1R 5'AAAAACATTGAAACATGCGACTT-3'). Sequence identity was determined by similarity using BLAST searches [32] against the NCBI database. Multiple alignments were performed using the MAFFT software [33]. Phylogenetic tree analysis was done using MEGA5 software [34] with Neighbor-Joining test, using the p-distance method with complete deletion and 10,000 replicates for bootstrap value. The molecular model of the L. longipalpis defensin was built based on the tertiary structure of the Anopheles gambiae [PDB:2NY8] [35] and Phormia terranovae [PDB:1ICA] [36] peptides present in the Protein Data Bank (PDB) [37]. The defensin sequence of L. longipalpis and $A$. gambiae were deposited on the molecular modeling server of the SWISS-MODEL (Automated Comparative Protein Modeling Server) [38,39] for the creation of a $3 \mathrm{D}$ prediction structure. The two structures were visually analyzed using the Swiss PDB Viewer 3.7 [40].

\section{Insects}

All experiments were performed using insects from a laboratory colony of L. longipalpis established from sand flies caught in Jacobina (Bahia, Brazil) using standard methods [41]. Insects were fed on 70\% sucrose ad libitum and fed on rabbit blood once a week. The insectary was kept under controlled conditions of temperature $\left(27 \pm 1^{\circ} \mathrm{C}\right)$, humidity (80-95\%), and photoperiod $(12 \mathrm{~h} / 12 \mathrm{~h})$. All procedures involving animals were performed in accordance with the UK Government (Home Office), HSE and EC regulations.

\section{Experimental bacterial feeds}

Escherichia coli (K12 RM148), Micrococcus luteus (A270), Ochrobactrum sp. (OM1,198 Jacobina colony isolate), Pantoea agglomerans (NCIMB11392), and Serratia marcescens (NCIMB 1377) were inoculated on Luria-Bertani (LB) agar plates and incubated overnight for 24 hours at $37^{\circ} \mathrm{C}$. Single colonies were transferred to polypropylene tubes, grown overnight in LB liquid medium, centrifuged at $13,200 \mathrm{rpm}$, re-suspended in $20 \%$ sucrose to $\mathrm{OD}_{600}=0.2$ and offered daily to female L. longipalpis through cotton wool. All bacteria were viable under these conditions over the duration of the experiment. Bacterial feed experiments were performed in parallel, one for each bacteria species, collecting 3 pools of 3 females each.

\section{Leishmania infections}

Leishmania infections were performed as previously described [42]. In brief, L. mexicana (strain MNYC/BZ/ $62 / \mathrm{M} 379$ ) were cultured at $26^{\circ} \mathrm{C}$ in M199 medium supplemented with $25 \mu \mathrm{g} / \mathrm{mL}$ gentamicin sulphate (Sigma), 1X BME vitamins (Gibco) and 10\% fetal calf serum (PAA). In preparation for infection, $2 \mathrm{~mL}$ of heatinactivated $\left(56^{\circ} \mathrm{C}\right.$ for 1 hour) rabbit blood was used to re-suspend cultured promastigotes to a final concentration of $2 \times 10^{6}$ promastigotes $/ \mathrm{mL}$. Rabbit blood seeded with parasites was offered to L. longipalpis through chick skin feeders and fully engorged flies were transferred to fresh cages. Sand flies were dissected at 5 days postinfection to confirm successful infections. Control flies were fed on rabbit blood only. The infection experiment was performed once, collecting 3 pools of 3 females each.

\section{Microinjections}

Newly emerged L. longipalpis were microinjected in the thorax with $18 \mathrm{~nL}$ of $E$. coli culture in LB medium at $\mathrm{OD}_{600}=0.2$ or $2 \times 10^{6} / \mathrm{mL}$. mexicana promastigotes using a Nanoject II microinjector. Control flies were either pricked in the thorax with a borosilicate needle or injected with $18 \mathrm{~nL}$ of autoclaved LB medium.

\section{RNA extractions and RT-PCR}

Total RNA was extracted from triplicate samples derived from pools of 3 whole larvae or adult L. longipalpis using TRI Reagent (Ambion). Semi-quantitative RT-PCR 
was performed using SuperScript III One-Step RT-PCR Platinum TaqHiFi (Invitrogen) according to manufacturer's instructions, with $10 \mathrm{ng}$ of template RNA and defensin-specific primers [30] (Defensin F 5'-GCCTGTG TGTTGTGGTTCT-3'; Defensin R 5'- GCATCTCCC CATCCTGTT-3'). Gene transcription was normalized based on the $60 \mathrm{~S}$ ribosomal protein L3 gene from $L$. longipalpis [GenBank: AM088777]. RT-PCR products were resolved on $2 \%$ agarose/ethidium bromide gels and band intensity was determined by densitometric measurement using the Image J software [43]. Differential transcription of genes was determined by the ratio between target gene band intensity and the corresponding $60 \mathrm{~S}$ L3 products obtained from multiplex RT-PCR reactions.

\section{Statistical analysis}

Statistical t-test analysis was performed using the GraphPad Prism software (San Diego, CA, USA). Results were expressed as mean \pm SEM. Significance was considered when $P<0.05$.

\section{Results}

Defensin gene sequence and phylogeny

The LlDef1 sequence was shown to contain 1034 nucleotides (nt) with the coding region between nucleotides 512 and 837 and an intron located between nucleotides 617 and 681 (Figure 1A). The 5'UTR sequence displayed putative binding sites for dorsal, caudal and HSF transcription factors and a polyadenylation signal site was found in the 3'UTR. The amino acid prediction indicates an 87 residues peptide, from which 40 correspond to the mature peptide $(4.23 \mathrm{kDa})$ (Figure 1A).

Multiple alignment analysis indicated conserved regions among all defensin sequences selected from blood feeding arthropods (data not shown) and the phylogenetic analysis showed that the L. longipalpis defensin sequence is closely related to defensins obtained from $P$. duboscqi and other nematocerans (Figure 1B). The putative L. longipalpis defensin tertiary structure was developed based on other insect defensins present in PDB. The analysis of the structure showed the expected architecture with two antiparallel $\beta$-sheets and one $\alpha$-helix (Figure 1C).
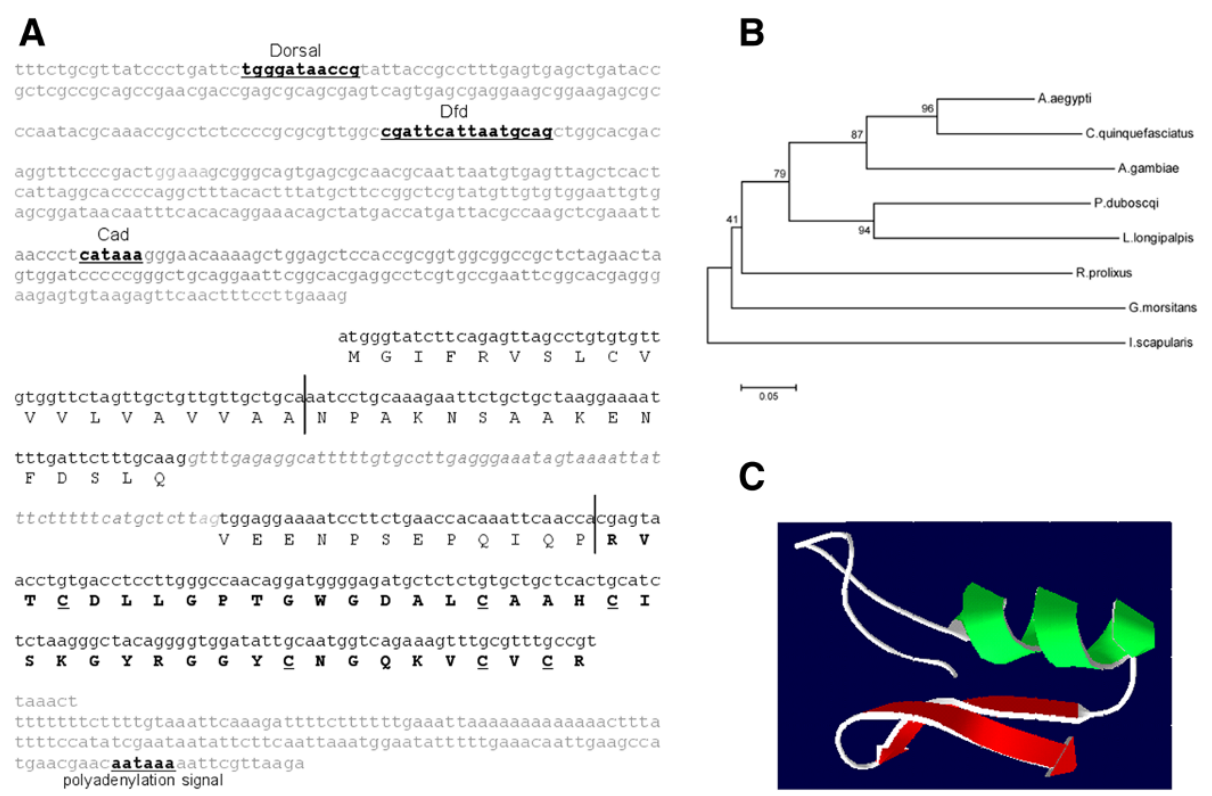

Figure 1 Sequence, phylogenetic analysis, and molecular modeling of Lutzomyia longipalpis defensin 1 (LIDef1). (A) The complete genomic sequence of the Lutzomyia longipalpis LIDef1 defensin gene containing 1034 nucleotides (nt) is shown. The 5'UTR region contains 518 nt and the 3'UTR 153 nt (lower case gray letters). In the 5'UTR region, potential binding sites for transcription factors Dorsal, Dfd and Caudal are shown (underlined bold lower case letters). The LIDef1 coding region contains 363 nucleotides with a 63 nt intron (gray lower case italic letters). The amino acid prediction indicates an 87 residues peptide (upper case letters), from which 40 correspond to the mature peptide (bold upper case letters). The first vertical bar limits the signal peptide and the second vertical bar divides the pre and pro-peptide. The 6 cysteines of the pro-peptide with the potential to generate 3 disulfide bonds are underlined and the polyadenylation site is indicated. (B) Neighbour-joining tree based on multi alignment created from defensins predicted amino acid sequences of L. longipalpis [JQ970473], A. aegypti [P81602.2], A. gambiae [AAC18575.1], P. duboscqi [P83404.3], Rhodnius prolixus [AAO74624.1], Glossina morsitans [Q8WTD4.1], Culex quinquefasciatus [AEQ27735.1] and Ixodes scapularis [XP_002401521.1], showing the phylogenetic relationship between L. longipalpis and other insect defensins. (C) Putative tertiary structure of the L. longipalpis defensin showing the characteristic architecture of arthropod defensins with two anti-parallel $\beta$-sheets (red) and an a-helix (green). 


\section{Transcription of defensin in L. longipalpis developmental stages}

RT-PCR was performed with RNA samples obtained from both immature and newly emerged sand flies. Actively feeding larvae (L3 and L4-f) expressed low defensin levels compared to non-feeding L4 larvae, although the difference was not statistically significant (Figure 2). Defensin expression was significantly lower in L3 and L4-f when compared to pupae. Similarly, newly emerged females showed a trend towards lower levels of defensin expression in comparison to pupae (Figure 2).

\section{Transcription of defensin in L. longipalpis fed on bacteria or Leishmania}

Defensin expression increased in female sand flies fed on four out of five bacteria tested when compared to sugar fed controls. This increased defensin expression was statistically significant 48 and $72 \mathrm{~h}$ after E. coli, Ochrobactrum sp. or S. marcescens ingestion (Figure 3A, B and C), and 24, 48 and $72 \mathrm{~h}$ after $M$. luteus ingestion (Figure 3E). Defensin expression decreased significantly 24 and $48 \mathrm{~h}$ after $P$. agglomerans ingestion and was unchanged in relation to controls at $72 \mathrm{~h}$ (Figure 3D). At the latest time point tested ( $96 \mathrm{~h}$ after infection), defensin expression returned to control levels observed in sugar-fed sand flies for all bacteria tested.

In adult females fed both on blood or blood containing L. mexicana, defensin expression increased sharply at $48 \mathrm{~h}$ and then slowly decreased from that time point until $144 \mathrm{~h}$ post-feed. In insects fed on blood containing

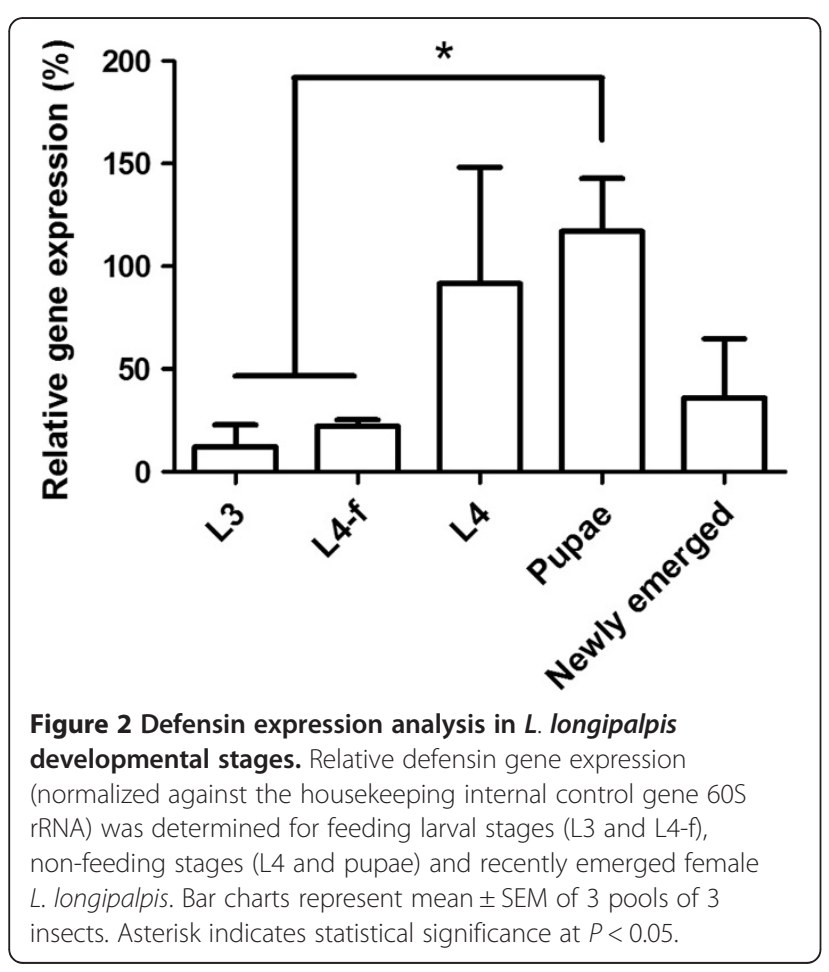

Leishmania defensin expression decreased significantly at $144 \mathrm{~h}$ in comparison to blood fed controls (Figure 3F).

Expression of defensin was also investigated in insects exposed to E. coli and L. mexicana through injection into the hemocoel. Pricking the insects (data not shown) or injecting female sand flies with autoclaved LB media generated an increase in defensin expression at 24 and $48 \mathrm{~h}$ after injection in comparison to uninjected sugarfed control sand flies (Figure 4). Similarly, female sand flies expressed higher levels of defensin mRNA at 24 and $72 \mathrm{~h}$ after $E$. coli injection when compared to the mockinjected control group (Figure 4). Insects injected with L. mexicana initially expressed significantly reduced levels of defensin mRNA at 24 and $48 \mathrm{~h}$ after injections, showing increased defensin expression at $72 \mathrm{~h}$ after injections when compared to the corresponding control group (Figure 4).

\section{Discussion}

In the present study we investigated and analyzed the expression profile of a defensin gene in L. longipalpis developmental stages, adult females infected orally with Gram-positive or negative bacteria and L. mexicana, or injected with E. coli or L. mexicana.

The L. longipalpis LlDef1 defensin gene contains two exons (134 and 172 nt respectively) interspersed with a $63 \mathrm{nt}$ intron. The presence of six cysteines at positions $52,57,61,71,77$ and 79 on the predicted amino acid sequence, with the potential to create three disulfide bonds, characterizes a defensin signature sequence [Pfam 01097]. We also sequenced 511 nt of the LlDef1 5'UTR and the analysis revealed that this gene is potentially under the control of at least two immune-related transcription factors: caudal and dorsal. Caudal encodes a DNA-binding nuclear transcription factor that plays a crucial role during development and innate immune response in Drosophila [44]. In Drosophila, Dorsal has its nuclear localization enhanced upon microbial challenge, interacting with Pelle, Tube, and Cactus during Toll activation to translocate and bind to NFKB-related sequences of AMP genes inside the nucleus [45]. The phylogenetic analysis showed that LIDef1 is similar to defensin sequences from other nematoceran diptera, being closely related to a P. duboscqi defensin [29].

High transcription levels were detected in non-feeding L. longipalpis L4 larvae and pupae. In Anopheles gambiae, defensin expression was detected in nonchallenged third and fourth instar larvae and pupae, reaching high expression levels after $E$. coli injections [46]. A Drosophila defensin was detected in third instar larvae only after bacterial challenge, although expression was detected in non-challenged pupae [47], similarly to what was observed in L. longipalpis and A. gambiae. No previous study explored the immune response in 


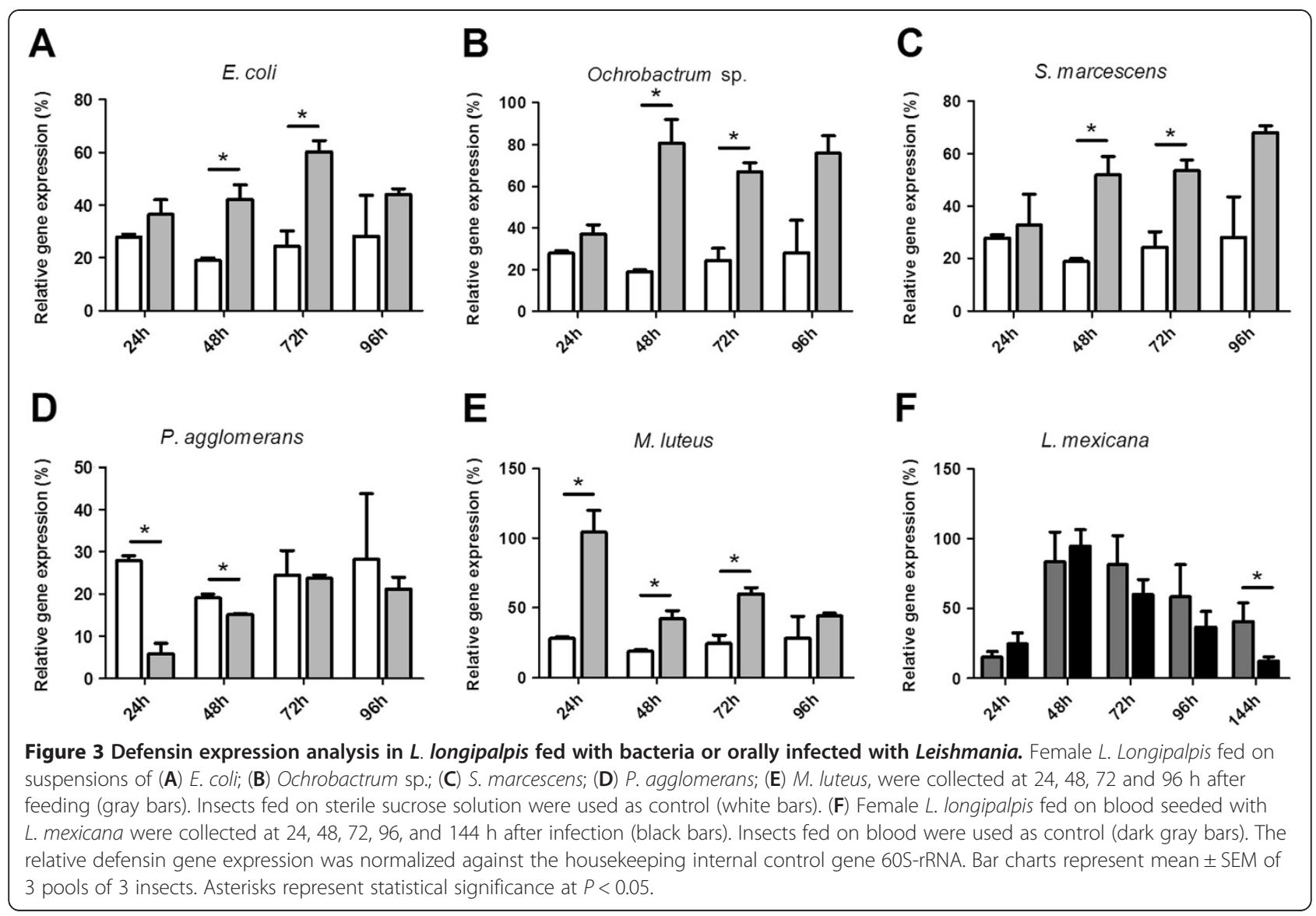

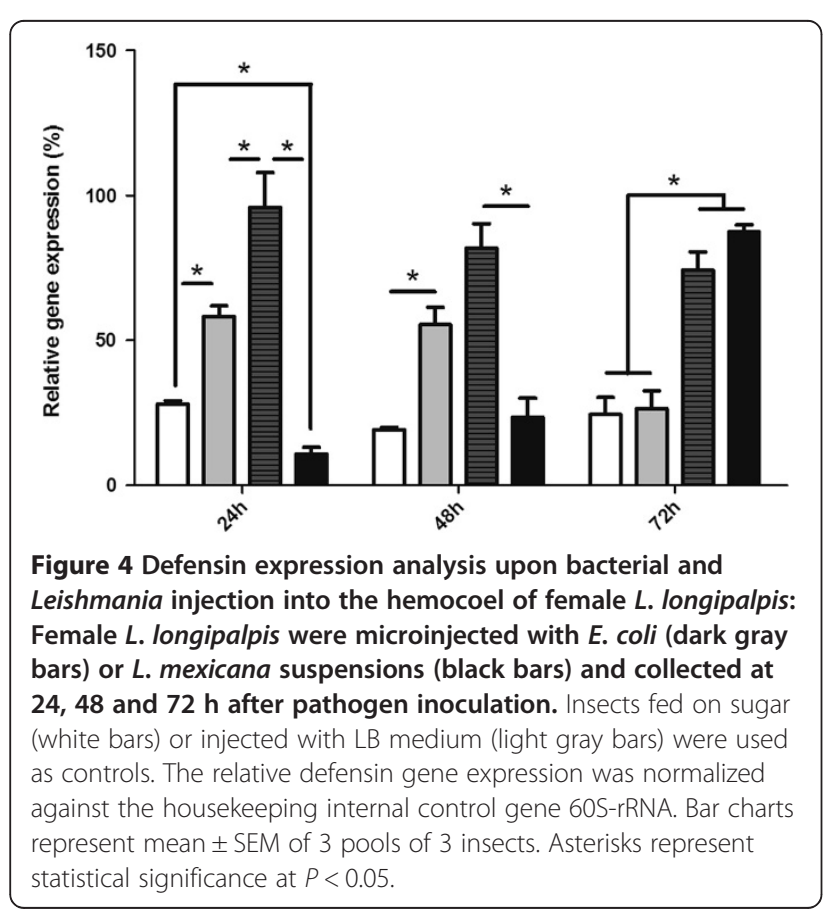

naturally feeding versus non-feeding larvae in the Diptera group. Since transstadial passage of bacteria from larvae to pupae and adult flies has been already reported for sandflies $[12,48,49]$, L. longipalpis nonfeeding L4 and pupae may trigger defensin expression to control and select gut microbiota during late L4 through pupation to emerged adult.

L. longipalpis were orally exposed to five different Gram-positive and Gram-negative bacteria. Defensin expression was found to increase with time upon infection with the Gram-negative E. coli, Ochrobactrum sp. and $S$. marcescens. Ochrobactrum sp. is acquired by $P$. duboscqi larvae from the environment [12] and it is plausible to consider that it is recognized by the insect immune system as a foreign antigen as much as E. coli. S. marcescens is entomopathogenic and was shown to trigger the $L$. longipalpis immune system through ROS increase [50]. Interestingly, infection with the Gram-negative $P$. agglomerans showed an initial decrease of defensin expression and a very constant level of expression over time matching control levels. This may be due to the fact that this bacterium, commonly found in Anopheles stephensi gut, is not pathogenic [51] and may not be recognized as a hazard by L. longipalpis. Insect defensins are known to be active mainly against Gram- 
positive bacteria [23,26,52]. Accordingly, flies exposed to the Gram-positive M. luteus showed a sharp upregulation of defensin mRNA during the early stages of infection ( $24 \mathrm{~h}$ post-feeding). Although defensin gene expression dropped considerably during the following 3 days, transcription was still significantly increased at 48 and $72 \mathrm{~h}$ post-feeding in comparison to controls.

These results suggest that sand flies are capable of mounting different innate immune responses against distinct bacterial species. A previous study that used the synergistic effects of lysozyme with antibacterial peptides revealed that $L$. longipalpis can successfully mount a humoral response against bacterial challenge and this response specifically discriminates between $M$. luteus and E. coli [53]. Although an increase of expression of a $4 \mathrm{kDa}$ peptide was detected in the hemolymph of both $M$. luteus and E. coli-injected L. longipalpis in comparison to mock-injected controls, an unknown $33 \mathrm{kDa}$ peptide could be detected in the hemolymph of the sand fly only when insects were challenged with $M$. luteus but not with E. coli [53]. These findings, and our present results, suggest that specific and discriminating immune responses are probably produced against the Grampositive and Gram-negative bacteria in L. longipalpis.

At $48 \mathrm{~h}$ after artificial blood feeding and artificial infection with L. mexicana adult female sand flies showed a dramatic increase of defensin expression that slowly decreased over time. This initial increase in defensin expression may be a response to the proliferation of sand fly gut microbiota caused by the ingestion of a nutrientrich blood meal as it was seen in P. duboscqi [12] and Aedes aegypti [54,55]. Interestingly, a defensin down regulation was observed starting at $72 \mathrm{~h}$ after Leishmania infection, reaching statistical significance at $144 \mathrm{~h}$ in comparison to blood-fed controls. Late infections were previously correlated with high numbers of Leishmania promastigotes within the sand fly gut [56]. Our present results indicate that high parasite number is correlated to low defensin expression. One explanation of this may be due to low levels of defensin expression at later time points after bloodfeeding, allowing for parasite survival and multiplication. On the other hand, if the defensin expression response is primarily towards bacterial molecular factors then the significant fall in defensin expression may be due to suppression of the gut bacterial population, via a competitive exclusion effect, in the presence of Leishmania.

A different transcription profile was reported in $P$. duboscqi infected with Leishmania major, where low levels of defensin expression were observed in the first day of infection whereas expression was strongly induced at four days after the Leishmania infection [29]. It is plausible that different phlebotomine sand flies and different Leishmania species may trigger diverse immune responses. This has been reported in mosquitoes, where different immune-related genes were modulated upon infection with various Plasmodium species $[57,58]$.

Expression of defensin in $L$. longipalpis after $L$. mexicana or E. coli intra-thoracic injection was also investigated. Pricked and LB medium-injected sand flies showed an increase in defensin expression in comparison to uninjected sugar-fed controls at 24 and $48 \mathrm{~h}$ post-injection. These results indicate that trauma by injection was sufficient to activate the innate immunity and induce defensin transcription in L. longipalpis. Cuticle pricking and mock-injection of dsRNA into the sand flies' hemocoel was shown to reduce the number of $L$. mexicana promastigotes within the midgut of $L$. longipalpis, possibly by nonspecific activation of the IMD pathway [59]. In A. aegypti, the injection of sterile saline induced the mosquito immune response and produced low but detectable levels of defensin mRNA [60]. Previous work in L. longipalpis showed that antimicrobial activity increased in sham-injected insects when compared to non-injected controls [53]. Similarly, our results demonstrated that control L. longipalpis microinjected with medium showed a significant increase in defensin expression at $24 \mathrm{~h}$ in comparison to controls, which was maintained until $48 \mathrm{~h}$ post-injection. In Drosophila Toll and IMD pathways can regulate different AMPs [61] and both can act synergistically [62]. This much is not yet explored in L. longipalpis.

Nimmo et al. [53] observed a significant increase in $L$. longipalpis humoral response against $E$. coli or $M$. luteus estimated by inhibition zone assays using hemolymph from bacteria-challenged insects. In addition, $P$. duboscq $i$ inoculated with Erwinia carotovora showed higher defensin expression in comparison to naive insects and bacteria-fed sand flies [29]. Although in line with results obtained for $P$. duboscqi, our results show a much subtler defensin expression in L. longipalpis upon bacterial injection. Similar results were obtained in A. aegypti inoculated with $E$. coli and M. luteus which showed 3 times higher levels of defensin peptides in their hemolymph when compared to sterile saline-injected insects [63]. These results confirm that mosquitoes and sand flies can mount an immune response through defensin expression upon bacterial challenge in their hemolymph.

L. longipalpis injected with L. mexicana showed a significant increase of defensin expression at $72 \mathrm{~h}$ post infection. Although the presence of Leishmania in the hemolymph does not occur in nature, it is possible that the ectopic presence of parasites within the hemolymph induced an immune response. It has been shown that Drosophila is capable of producing an immune response against injected Plasmodium gallinaceum oocytes [64]. Defensin reduction at 24 and $48 \mathrm{~h}$ after Leishmania injection may be a counterbalance caused by activation 
of the IMD pathway triggering other AMP, but not DefLl1. Later, at $72 \mathrm{~h}$, L. longipalpis is able to express high levels of defensin. To our knowledge, this is the first report of an immune response in sandflies after parasite injection. Investigation of other Toll or IMD related AMPs could address and clarify this hypothesis related to the sandflies immune response to Leishmania injection in hemolymph, but none has been described up to date.

\section{Conclusion}

Here, we have described a L. longipalpis defensin gene similar to a $P$. duboscqi defensin, modulated by bacterial feed and injection and Leishmania infections. These genes are the only defensins so far described for both sand fly species but the presence of multiple defensin genes and other AMPs co-existing in sand flies is possible. Defensin isoforms with distinct transcriptional patterns and putative distinct roles were previously described in A. gambiae [65]. The difference in defensin expression levels upon bacterial challenge observed for the New and Old World species may therefore be due to expression of different defensin isoforms acting concertedly to control bacterial proliferation within the sand fly midgut and hemolymph. Our results suggest that $L$. longipalpis is able to mount a differential response of defensin expression upon bacterial feeding and bacterial injection into the hemocoel and Leishmania gut infection.

\section{Competing interests}

The authors declare no competing interests.

\section{Authors' contributions}

RJD and YMT designed the experiments. ELT and MOA carried out the biological and molecular experiments. ANP performed sequence and phylogenetic analysis. ELT, MRVS, ANP, RJD and YMT wrote the manuscript. All authors read and approved the final version of the manuscript.

\section{Acknowledgements}

This work was funded by The Leverhulme Trust (www.leverhulme.co.uk) ref F/00 808/C; Coordenação de Aperfeiçoamento de Pessoal de Nível Superior CAPES-PDEE; Fundação Carlos Chagas Filho de Amparo à Pesquisa do Estado do Rio de Janeiro - FAPERJ; Instituto Oswaldo Cruz and PAPES VI-FIOCRUZ.

\section{Author details}

'Laboratório de Biologia Molecular de Parasitos e Vetores, Instituto Oswaldo Cruz-Fiocruz, Rio de Janeiro, RJ, Brazil. ${ }^{2}$ School of Health and Medicine, Lancaster University, Lancaster, England, UK. ${ }^{3}$ Vector Group, Liverpool School of Tropical Medicine, Liverpool, England, UK. ${ }^{4}$ Present address: Yale School of Public Health - LEPH, New Haven, CT, USA.

Received: 13 December 2012 Accepted: 14 December 2012 Published: 11 January 2013

\section{References}

1. Cohnstaedt LW, Beati L, Caceres AG, Ferro C, Munstermann LE: Phylogenetics of the phlebotomine sand fly group Verrucarum (Diptera: Psychodidae: Lutzomyia). AmJTrop Med Hyg 2011, 84:913-922.

2. Ready PD: Should sand fly taxonomy predict vectorial and ecological traits? J Vector Ecol 2011, 36(Suppl 1):S17-S22.
3. Ramalho-Ortigao M, Saraiva EM, Traub-Cseko YM: Sand Fly-Leishmania Interactions: Long Relationships are Not Necessarily Easy. The Open Parasitology Journal 2010, 4:195-204.

4. Svarovska A, Ant TH, Seblova V, Jecna L, Beverley SM, Volf P: Leishmania major glycosylation mutants require phosphoglycans (lpg2-) but not lipophosphoglycan (lpg1-) for survival in permissive sand fly vectors. PLoS Negl Trop Dis 2010, 4:e580

5. Rogers ME, Hajmova M, Joshi MB, Sadlova J, Dwyer DM, Volf P, Bates PA: Leishmania chitinase facilitates colonization of sand fly vectors and enhances transmission to mice. Cell Microbiol 2008, 10:1363-1372.

6. Kamhawi S, Ramalho-Ortigao M, Pham VM, Kumar S, Lawyer PG, Turco SJ, Barillas-Mury C, Sacks DL, Valenzuela JG: A role for insect galectins in parasite survival. Cell 2004, 119:329-341.

7. Sant'anna MR, Diaz-Albiter H, Mubaraki M, Dillon RJ, Bates PA: Inhibition of trypsin expression in Lutzomyia longipalpis using RNAi enhances the survival of Leishmania. Parasit Vectors 2009, 2:62.

8. Telleria EL, de Araujo AP, Secundino NF, d'Avila-Levy CM, Traub-Cseko YM: Trypsin-like serine proteases in Lutzomyia longipalpis-expression, activity and possible modulation by Leishmania infantum chagasi. PLoS One 2010, 5:e10697.

9. Pimenta PF, Modi GB, Pereira ST, Shahabuddin M, Sacks DL: A novel role for the peritrophic matrix in protecting Leishmania from the hydrolytic activities of the sand fly midgut. Parasitology 1997, 115(Pt 4):359-369.

10. Guernaoui S, Garcia D, Gazanion E, Ouhdouch Y, Boumezzough A, Pesson B, Fontenille D, Sereno D: Bacterial flora as indicated by PCR-temperature gradient gel electrophoresis (TGGE) of 16S rDNA gene fragments from isolated guts of phlebotomine sand flies (Diptera: Psychodidae). J Vector Ecol 2011, 36(Suppl 1):S144-S147.

11. Hillesland H, Read A, Subhadra B, Hurwitz I, McKelvey R, Ghosh K, Das P, Durvasula R: Identification of aerobic gut bacteria from the kala azar vector, Phlebotomus argentipes: a platform for potential paratransgenic manipulation of sand flies. AmJTrop Med Hyg 2008, 79:881-886.

12. Volf $P$, Kiewegova $A$, Nemec $A$ : Bacterial colonisation in the gut of Phlebotomus duboseqi (Diptera: Psychodidae): transtadial passage and the role of female diet. Folia Parasitol 2002, 49:73-77.

13. Azpurua J, De La Cruz D, Valderama A, Windsor D: Lutzomyia sand fly diversity and rates of infection by Wolbachia and an exotic Leishmania species on Barro Colorado Island, Panama. PLoS Negl Trop Dis 2010, 4:e627.

14. Gouveia C, Asensi MD, Zahner V, Rangel EF, Oliveira SM: Study on the bacterial midgut microbiota associated to different Brazilian populations of Lutzomyia longipalpis (Lutz \& Neiva) (Diptera: Psychodidae). Neotrop Entomol 2008, 37:597-601.

15. Oliveira SM, Moraes BA, Goncalves CA, Giordano-Dias CM, D'Almeida JM, Asensi MD, Mello RP, Brazil RP: Prevalence of microbiota in the digestive tract of wild females of Lutzomyia longipalpis Lutz \& Neiva, 1912) (Diptera: Psychodidae). Rev Soc Bras Med Trop 2000, 33:319-322.

16. McCarthy CB, Diambra LA, Rivera Pomar RV: Metagenomic analysis of taxa associated with Lutzomyia longipalpis, vector of visceral leishmaniasis, using an unbiased high-throughput approach. PLoS Negl Trop Dis 2011, 5:e1304.

17. Azambuja P, Garcia ES, Ratcliffe NA: Gut microbiota and parasite transmission by insect vectors. Trends Parasitol 2005, 21:568-572

18. Cirimotich CM, Dong Y, Garver LS, Sim S, Dimopoulos G: Mosquito immune defenses against Plasmodium infection. Dev Comp Immunol 2010, 34:387-395.

19. Feldhaar H, Gross R: Immune reactions of insects on bacterial pathogens and mutualists. Microbes Infect 2008, 10:1082-1088.

20. Welchman DP, Aksoy S, Jiggins F, Lemaitre B: Insect immunity: from pattern recognition to symbiont-mediated host defense. Cell Host Microbe 2009, 6:107-114

21. Boulanger N, Bulet $P$, Lowenberger C: Antimicrobial peptides in the interactions between insects and flagellate parasites. Trends Parasitol 2006, 22:262-268.

22. Ferrandon D, Imler JL, Hetru C, Hoffmann JA: The Drosophila systemic immune response: sensing and signalling during bacterial and funga infections. Nat Rev Immunol 2007, 7:862-874.

23. Bulet $P$, Hetru C, Dimarcq JL, Hoffmann D: Antimicrobial peptides in insects; structure and function. Dev Comp Immunol 1999, 23:329-344

24. Lamberty M, Ades S, Uttenweiler-Joseph S, Brookhart G, Bushey D, Hoffmann JA, Bulet P: Insect immunity. Isolation from the lepidopteran Heliothis virescens of a novel insect defensin with potent antifungal activity. J Biol Chem 1999, 274:9320-9326. 
25. Mandrioli M, Bugli S, Saltini S, Genedani S, Ottaviani E: Molecular characterization of a defensin in the IZD-MB-0503 cell line derived from immunocytes of the insect Mamestra brassicae (Lepidoptera). Biol Cell 2003, 95:53-57.

26. Vizioli J, Richman AM, Uttenweiler-Joseph S, Blass C, Bulet P: The defensin peptide of the malaria vector mosquito Anopheles gambiae: antimicrobial activities and expression in adult mosquitoes. Insect Biochem Mol Biol 2001, 31:241-248.

27. Kokoza V, Ahmed A, Woon Shin S, Okafor N, Zou Z, Raikhel AS: Blocking of Plasmodium transmission by cooperative action of Cecropin $\mathrm{A}$ and Defensin A in transgenic Aedes aegypti mosquitoes. Proc Natl Acad Sci U S A 2010, 107:8111-8116.

28. Kulkarni MM, McMaster WR, Kamysz W, McGwire BS: Antimicrobial peptideinduced apoptotic death of leishmania results from calcium-de pend ent, caspase-independent mitochondrial toxicity. J Biol Chem 2009, 284:15496-15504.

29. Boulanger $N$, Lowenberger $C$, Volf $P$, Ursic R, Sigutova L, Sabatier L, Svobodova M, Beverley SM, Spath G, Brun R, et al: Characterization of a defensin from the sand fly Phlebotomus duboscqi induced by challenge with bacteria or the protozoan parasite Leishmania major. Infect Immun 2004, 72:7140-7146.

30. Pitaluga AN, Mason PW, Traub-Cseko YM: Non-specific antiviral response detected in RNA-treated cultured cells of the sandfly, Lutzomyia longipalpis. Dev Comp Immunol 2008, 32:191-197.

31. Pitaluga AN, Beteille V, Lobo AR, Ortigao-Farias JR, Davila AM, Souza AA, Ramalho-Ortigao JM, Traub-Cseko YM: EST sequencing of blood-fed and Leishmania-infected midgut of Lutzomyia longipalpis, the principal visceral leishmaniasis vector in the Americas. Mol Genet Genomics 2009, 282:307-317.

32. Altschul SF, Gish W, Miller W, Myers EW, Lipman DJ: Basic local alignment search tool. J Mol Biol 1990, 215:403-410.

33. Katoh K, Misawa K, Kuma K, Miyata T: MAFFT: a novel method for rapid multiple sequence alignment based on fast Fourier transform. Nucleic Acids Res 2002, 30:3059-3066.

34. Tamura K, Peterson D, Peterson N, Stecher G, Nei M, Kumar S: MEGA5: molecular evolutionary genetics analysis using maximum likelihood, evolutionary distance, and maximum parsimony methods. Mol Biol Evol 2011, 28:2731-2739.

35. Landon C, Barbault F, Legrain M, Guenneugues M, Vovelle F: Rational design of peptides active against the gram positive bacteria Staphylococcus aureus. Proteins 2008, 72:229-239.

36. Cornet B, Bonmatin JM, Hetru C, Hoffmann JA, Ptak M, Vovelle F: Refined three-dimensional solution structure of insect defensin A. Structure 1995 3:435-448

37. Berman HM, Westbrook J, Feng Z, Gilliland G, Bhat TN, Weissig H, Shindyalov IN, Bourne PE: The Protein Data Bank. Nucleic Acids Res 2000, 28:235-242.

38. Arnold K, Bordoli L, Kopp J, Schwede T: The SWISS-MODEL workspace: a web-based environment for protein structure homology modelling. Bioinformatics 2006, 22:195-201.

39. Kiefer F, Arnold K, Kunzli M, Bordoli L, Schwede T: The SWISS-MODEL Repository and associated resources. Nucleic Acids Res 2009, 37:D387-D392.

40. Guex N, Peitsch MC: SWISS-MODEL and the Swiss-PdbViewer: an environment for comparative protein modeling. Electrophoresis 1997 18:2714-2723.

41. Modi GB: Care and maintenance of phlebotomine sandfly colonies. In The molecular biology of insect disease vectors: a methods manual. Edited by Crampton JM, Beard CB, Louis C. London (United Kingdom): Chapman and Hall Ltd; 1997:21-30.

42. Sant'Anna MR, Alexander B, Bates PA, Dillon RJ: Gene silencing in phlebotomine sand flies: Xanthine dehydrogenase knock down by dsRNA microinjections. Insect Biochem Mol Biol 2008, 38:652-660.

43. Abramoff MD, Magalhaes PJ, Ram SJ: Image Processing with ImageJ. Biophotonics Int 2004, 11:36-42.

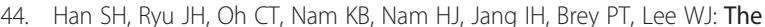
moleskin gene product is essential for Caudal-mediated constitutive antifungal Drosomycin gene expression in Drosophila epithelia. Insect Mol Biol 2004, 13:323-327.

45. Valanne S, Wang JH, Ramet M: The Drosophila Toll signaling pathway. $\mathrm{J}$ Immunol 2011, 186:649-656.
46. Dimopoulos G, Richman A, Muller HM, Kafatos FC: Molecular immune responses of the mosquito Anopheles gambiae to bacteria and malaria parasites. Proc Natl Acad Sci U S A 1997, 94:11508-11513.

47. Dimarcq JL, Hoffmann D, Meister M, Bulet $P$, Lanot R, Reichhart JM, Hoffmann JA: Characterization and transcriptional profiles of a Drosophila gene encoding an insect defensin. A study in insect immunity. Eur J Biochem 1994, 221:201-209.

48. Hurwitz I, Hillesland H, Fieck A, Das P, Durvasula R: The paratransgenic sand fly: a platform for control of Leishmania transmission. Parasit Vectors 2011, 4:82.

49. Peterkova-Koci K, Robles-Murguia M, Ramalho-Ortigao M, Zurek L: Significance of bacteria in oviposition and larval development of the sand fly Lutzomyia longipalpis. Parasit Vectors 2012, 5:145.

50. Diaz-Albiter H, Sant' Anna MR, Genta FA, Dillon RJ: Reactive oxygen species-mediated immunity against Leishmania mexicana and Serratia marcescens in the phlebotomine sand fly Lutzomyia longipalpis. J Biol Chem 2012, 287:23995-24003.

51. Riehle MA, Moreira CK, Lampe D, Lauzon C, Jacobs-Lorena M: Using bacteria to express and display anti-Plasmodium molecules in the mosquito midgut. Int J Parasitol 2007, 37:595-603.

52. Zhou J, Liao M, Ueda M, Gong H, Xuan X, Fujisaki K: Sequence characterization and expression patterns of two defensin-like antimicrobial peptides from the tick Haemaphysalis longicornis. Peptides 2007, 28:1304-1310.

53. Nimmo DD, Ham PJ, Ward RD, Maingon R: The sandfly Lutzomyia longipalpis shows specific humoral responses to bacterial challenge. Med Vet Entomol 1997, 11:324-328.

54. Antonova Y, Alvarez KS, Kim YJ, Kokoza V, Raikhel AS: The role of NFkappaB factor REL2 in the Aedes aegypti immune response. Insect Biochem Mol Biol 2009, 39:303-314.

55. Oliveira JH, Goncalves RL, Lara FA, Dias FA, Gandara AC, Menna-Barreto RF, Edwards MC, Laurindo FR, Silva-Neto MA, Sorgine MH, Oliveira PL: Blood meal-derived heme decreases ROS levels in the midgut of Aedes aegypti and allows proliferation of intestinal microbiota. PLOS Pathog 2011, 7:e1001320.

56. Bates PA: Transmission of Leishmania metacyclic promastigotes by phlebotomine sand flies. Int J Parasitol 2007, 37:1097-1106.

57. Dong Y, Aguilar R, Xi Z, Warr E, Mongin E, Dimopoulos G: Anopheles gambiae immune responses to human and rodent Plasmodium parasite species. PLoS Pathog 2006, 2:e52.

58. Bahia AC, Kubota MS, Tempone AJ, Pinheiro WD, Tadei WP, Secundino NF, Traub-Cseko YM, Pimenta PF: Anopheles aquasalis Infected by Plasmodium vivax displays unique gene expression profiles when compared to other malaria vectors and plasmodia. PLoS One 2010, 5:e9795.

59. Telleria EL, Sant'anna MR, Ortigao-Farias JR, Pitaluga AN, Dillon VM, Bates PA, Traub-Cseko YM, Dillon RJ: Caspar-like Gene Depletion Reduces Leishmania Infection in Sand Fly Host Lutzomyia longipalpis. J Biol Chem 2012, 287:12985-12993.

60. Lowenberger CA, Kamal S, Chiles J, Paskewitz S, Bulet P, Hoffmann JA, Christensen BM: Mosquito-Plasmodium interactions in response to immune activation of the vector. Exp Parasitol 1999, 91:59-69.

61. De Gregorio E, Spellman PT, Tzou P, Rubin GM, Lemaitre B: The Toll and Imd pathways are the major regulators of the immune response in Drosophila. EMBO J 2002, 21:2568-2579.

62. Tanji T, Hu X, Weber AN, Ip YT: Toll and IMD pathways synergistically activate an innate immune response in Drosophila melanogaster. $\mathrm{Mol}$ Cell Biol 2007, 27:4578-4588.

63. Lowenberger C, Bulet $P$, Charlet M, Hetru C, Hodgeman B, Christensen BM, Hoffmann JA: Insect immunity: isolation of three novel inducible antibacterial defensins from the vector mosquito, Aedes aegypti. Insect Biochem Mol Biol 1995, 25:867-873.

64. Schneider D, Shahabuddin M: Malaria parasite development in a Drosophila model. Science 2000, 288:2376-2379.

65. Meredith JM, Hurd H, Lehane MJ, Eggleston P: The malaria vector mosquito Anopheles gambiae expresses a suite of larval-specific defensin genes. Insect Mol Biol 2008, 17:103-112.

doi:10.1186/1756-3305-6-12

Cite this article as: Telleria et al:: Bacterial feeding, Leishmania infection and distinct infection routes induce differential defensin expression in Lutzomyia longipalpis. Parasites \& Vectors 2013 6:12. 